\title{
IOT Based Application for Monitoring and Predicting Air Quality in the environment
}

\author{
Vaishnavi Kulkarni \\ dept. of computer engineering \\ Dr. D.Y. Patil School of engineering and \\ technology \\ Pune, Maharashtra \\ kulkarnivaishnavi1698@gmail.com \\ Abhijeet Kumar Mandal \\ dept. of computer engineering \\ Dr. D.Y. Patil School of engineering and \\ technology \\ Pune, Maharashtra \\ abhijeetkumar8795@gmail.com
}

\author{
Priyanka Mudaliar \\ dept. of computer engineering \\ Dr. D.Y. Patil School of engineering and \\ technology \\ Pune, Maharashtra \\ pri.mudliar@gmail.com \\ Prof. Kranti M Kamble \\ dept. of electronics \& telecommunications \\ Dr. D.Y. Patil School of engineering and \\ technology \\ Pune, Maharashtra \\ kranti.kamble@dypic.in
}

\author{
Rutuja Jaid \\ dept. of computer engineering \\ Dr. D.Y. Patil School of engineering and \\ technology \\ Pune, Maharashtra \\ rutujajaid97@gmail.com
}

\begin{abstract}
India has been dealing with pollution for a long time. As the matter of fact, in February, India was home to six out of 10 of the world's most polluted cities. While on the contrary, atmospheric pollution, surrounding pollutants are about 1000 times more likely to be transmitted to the lungs, causing diseases The main sources of air pollution are motor vehicle emissions, illegal industrial activities, harmful pesticides, and many times we see LPG gas leakages and cylinder truck accidents on the road which are harmful to us and can take our lives. Therefore, poor air quality results in many health complications, such as heart disease, lung cancer, and breathing problems like asthma. It is important to regulate air pollution and also to incorporate technology, sensors, and software systems to ensure that air pollution is closely monitored. Our efforts in this project are to create an application that can be used to track air quality to take preventive steps to keep our living environment healthy. The program is user-friendly and works to produce real-time air quality warnings as a preventive mechanism. Our key contribution is to build a monitoring system for air quality that senses the real-time data of surrounding parameters such as carbon monoxide and PM level and warns people when the sum of these elements goes above a certain limit and presents the data in a format that is easy to understand.
\end{abstract}

Keywords- Air quality, Raspberry pi, Internet Of Things (IoT), Air Quality Index (AQI), Sensors, Air pollution.

\section{INTRODUCTION}

One of the environmental issues that should not be overlooked is air pollution. There is a growing risk of respiratory disorders and lung diseases resulting from it, with declining air quality all over the globe due to industrial and vehicular emissions. This system which is an android app is used to sense the air quality displays the real state of the air. The project aims to track air quality using various sensors like MQ-135 is an air quality sensor, which is sensitive for benzene, smoke, and other pollutants, MQ-4 is methane and CNG sensor, MQ-7 is a carbon monoxide sensor and MQ-6 is an LPG sensor. These are used in combination with the raspberry pi to calculate AQI and notify the user. Solving the drawbacks of existing air quality sensors this application can be used to monitor various gases at a time. Helping the government to formulate an indexing scheme for air pollution categories in India is the key motive behind the research and development of the system. The project is to develop an implementation of the air pollution monitoring system; a detection system for various environmental information is built in this project.

\section{LITERATURE. SURVEY}

[1] Ajitesh Kumar, Mona Kumari and Harsh Gupta “ Design and Analysis of IoT based air quality monitoring system "Feb 28-29, 2020: This paper proposes a costeffective observation system for air quality that defines the continuous information covering various boundaries such as smoke, carbon monoxide and PM level and alerts people when the quantity of these components passes a clear cutoff and displays the information in a realistic configuration without any issue. Later on, additionally detecting hubs can be added to expand the framework. The significant preferred position of this framework is that it is versatile, little and cost-effective. We have also introduced the execution of an ease IoT based air quality checking framework.

[2] Pratishtha Agnihotri, Sonam Tiwari and Dr. Devendra Mohan" Design of Air pollution monitoring system using wireless sensor network" 2019: In this paper, the authors have proposed a new scheme based on asynchronous data obtained by our monitoring system to carry out the finegrained and actual prediction of AQI. Asynchronous sensing data and spatial-temporal-meteorological relationships are provided. The prediction procedures are carefully planned based on the CG model and an optimization problem occurs. They seek to optimize the problem by an algorithm that integrates a genetic algorithm and closed-form derivation. The benefit of the proposed solution over existing ones is assessed by our monitoring system over the data set collected.

[3] Ravi Kishore Kodali and Sairi pathuri Sasweth C. Rajnarayanan "Smart Indoor air pollution monitoring station" Jan 22-24 2020, Coimbatore India: In this paper the author has proposed a surrounding air contamination detecting framework can give ongoing estimation of five generally significant for human well-being air boundaries and move it to more significant level applications for 
examination and anticipating. Estimated information is reinforced along with timestamp and GPS position. The gadget spares information into on-board SD card with capacity to be moved to a have PC by direct USB association or through Wi-Fi transmission.

[4] Zixuan Bai "Real time prediction for Fine-grained air quality monitoring system with asynchronous sensing", Perking university 2019: The authors have stated that because of the disturbing degrees of contamination in a portion of the significant urban communities of world, persistent observing of air quality has become a significant issue. By utilizing remote detecting system alongside rapid web association, the checking and examination process has become effective. Such mechanized frameworks are precise, history of the boundaries is moreover put away which can be utilized. The WSN checking frameworks can likewise be executed for different sorts of contamination, water contamination, soil contamination or radioactive pollution.

[5] Mykhailo Lobur and Dmytro Korpyljov and Nazariy Jaworski "Arduino Based Ambient Air Pollution Sensing System" University of Exeter, 2020: The paper presents a remote sensor organize for air contamination observing in light of IOT is useful for the business as well as everyday citizens too. As the contamination information will be accessible with individual and one can see where the contamination level is more around then and the individuals having respiratory sicknesses may abstain from following that way for that specific time of time. Advanced cells are extremely regular now daily. Indeed, even the contamination because of ventures can be checked and the information can be made accessible on the web so that, the important activity to diminish the contamination might be started furthermore.

[6] Md. Mohiuddin Ahmed, Suraiya Banu and Bijan Paul" Real-time Air Quality Monitoring System for Bangladesh's perspective based on Internet of things " International Conference on Electrical Information and Communication Technology (EICT), 7-9 December 2017: The author claimed in this paper that the dangerous levels of pollution in a few parts of the globe and the routine monitoring of air quality are now a big concern now a days. Using the self designed and wireless infrastructure network along with information with high speed web access, the supervising, monitoring and regulating has become esay and readily approachable by common man. These automated systems are reliable and precise. For different kinds of emissions, WSN control systems can be introduced. To achieve accurate data in real time, the high efficiency communication protocol along with the sensor network is used.

[7] Octavian A. Postolache, J. M. Dias Pereira, and P. M. B. Silva Girão" Smart Sensors Network for Air Quality Monitoring Applications" September 2009.The creation of an IoT-based monitoring platform for indoor air quality is discussed in this paper. Experiments were conducted to validate the measurement system for air quality used. A system suggested by the Ministry of the Environment, Korea, was based on the platform. We checked the accuracy of the monitoring of indoor air quality and the device's desirable efficiency. In addition, tests using the platform were performed and demonstrated the air quality monitoring platform's acceptable efficiency and convenience. The author concentrated in this paper on checking the device's reliability and implementing the platform.
[8] Somansh Kumar and Ashish Jasuja "Air Quality Monitoring System Based on IoT using Raspberry Pi" International Conference on Computing, Communication, Communication and Automation (ICCCA2017): The author states that the proposed framework gives minimal effort, low force, conservative and exceptionally exact framework for checking the condition with the committed sensors remotely from any place in this world. An ideal trade off among exactness and cost is accomplished by utilizing single board minicomputer Raspberry pi and proper sensors prompting a well-grounded framework. Air quality observing framework can be more worthwhile if poisons like Sulfur dioxide, nitrogen dioxide, ground level ozone and so forth are additionally checked.

[9] Ajay Chaturvedi and Laxmi Shrivastava "IOT Based Wireless Sensor Network for Air Pollution Monitoring "Jan 2020: This paper the author has stated the execution of an estimating framework for air quality checking. Two structures are ace postured for remote correspondence between the detecting hubs what's more, a PC that deals with the entire framework. The frameworks are especially appropriate for indoor applications. The yield of the preowned gas sensors depends not just on the cross impact of the essential estimated gas yet in addition on external impact factors, to be specific temperature and mugginess. The impact of this cross effect on the exactness of the estimation can be limited utilizing moreover neural systems.

[10] JunHo Jo, ByungWan Jo, JungHoon Kim, SungJun Kim and WoonYong Han "Development of an IoT Based Indoor Air Quality Monitoring Platform" January 2020: The author states, with the correct usage of proposed framework they can decrease risky mishaps that happens all through the nation. This arrangement can be introduced in house for house well-being just as any industry or crowed work environment to keep up the air quality safe and lift their work speed. One of the primary explanation is, outrageous pneumatic force. So, in future they need to expand this framework to recognize pneumatic force of evaporator so it can forestall mishaps and spare numerous lives just as modern misfortune.

TABLE I. Literature SURVEY ADVANTAGES AND DISADVANTAGES

\begin{tabular}{|c|c|c|}
\hline Author name & Advantage & Disadvantage \\
\hline A kumar & $\begin{array}{l}\text { Smart design and use } \\
\text { of buzzer is a good } \\
\text { way to alert the user. }\end{array}$ & $\begin{array}{l}\text { Needs some kind of } \\
\text { SMS or app } \\
\text { notification in case of } \\
\text { buzzer malfunction }\end{array}$ \\
\hline B. Bathiya & $\begin{array}{l}\text { Use of WSN allows us } \\
\text { to cover a large area } \\
\text { which is a limitation } \\
\text { of others system } \\
\text { which working in } \\
\text { small area. }\end{array}$ & $\begin{array}{l}\text { Any malfunction of } \\
\text { sensory node will } \\
\text { result in huge loss of } \\
\text { data of a large area }\end{array}$ \\
\hline M. Lobur & $\begin{array}{l}\text { Use a lot of different } \\
\text { sensors which gives a } \\
\text { different viewpoint of } \\
\text { calculation of air } \\
\text { pollution }\end{array}$ & $\begin{array}{l}\text { Use of Arduino which } \\
\text { is not as powerful as } \\
\text { raspberry pi and is } \\
\text { difficult to connect to } \\
\text { the internet }\end{array}$ \\
\hline M. M. Ahmed & $\begin{array}{l}\text { Uses a real timeout } \\
\text { monitoring system } \\
\text { with mobile app } \\
\text { giving security and } \\
\text { accurate data }\end{array}$ & $\begin{array}{l}\text { Since this was made in } \\
\text { Bangladesh which has } \\
\text { regular gas leak, the } \\
\text { project emphasis on } \\
\text { finding those gases } \\
\text { more which is not } \\
\text { applicable to country } \\
\text { like India }\end{array}$ \\
\hline
\end{tabular}




\begin{tabular}{|l|l|l|}
\hline S. Kumar & $\begin{array}{l}\text { Good system with } \\
\text { back testing of data in } \\
\text { India, using latest } \\
\text { technology and } \\
\text { sensors }\end{array}$ & $\begin{array}{l}\text { Does not monitor } \\
\text { some key pollutant } \\
\text { like O3, SO2, etc., } \\
\text { which is crucial for } \\
\text { AQI calculation. }\end{array}$ \\
\hline A. Chaturvedi & $\begin{array}{l}\text { Covers a large area } \\
\text { using WSN and uses } \\
\text { some unique sensors }\end{array}$ & $\begin{array}{l}\text { Uses computers } \\
\text { instead of sensory } \\
\text { nodes which makes it } \\
\text { very expensive }\end{array}$ \\
\hline JunHo Jo & $\begin{array}{l}\text { Made a very powerful } \\
\text { application and solid } \\
\text { connection to the IOT } \\
\text { system }\end{array}$ & $\begin{array}{l}\text { Author admits to not } \\
\text { testing accuracy of } \\
\text { sensors as much as } \\
\text { required }\end{array}$ \\
\hline O. A. Postolache & $\begin{array}{l}\text { Innovative approach } \\
\text { which combine IOT } \\
\text { and neural networks }\end{array}$ & $\begin{array}{l}\text { The tin di oxide e } \\
\text { sensors used are } \\
\text { sensitive to all types of } \\
\text { gases which reduces } \\
\text { accuracy }\end{array}$ \\
\hline Z. Bai & $\begin{array}{l}\text { A synchronous } \\
\text { sensing gives much } \\
\text { more accurate data as } \\
\text { compared to } \\
\text { synchronous sensing }\end{array}$ & $\begin{array}{l}\text { It is very complex to } \\
\text { implement and a } \\
\text { synchronous data } \\
\text { cannot be used on lot } \\
\text { of algorithm like } \\
\text { LSTM. }\end{array}$ \\
\hline
\end{tabular}

\section{METHODOLOGY}

Figure 1 shows the block diagram of the system. Arduino can be interfaced with raspberry pi and its (Analog to Digital Conversion) ADC is very effective. The sensor framework consisting of many sensors is interfaced to Arduino Board. The Arduino board, Raspberry pi module is connected with the help of USB cable. The data that is collected from sensors are sent to Google firebase through Raspberry pi module.

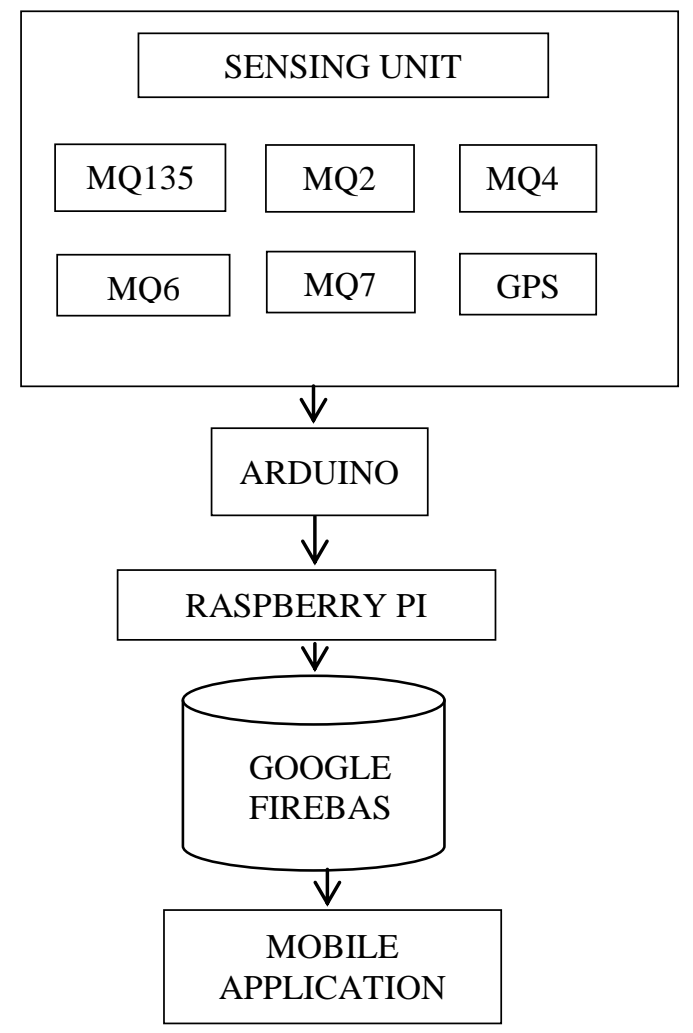

Fig. 1. Block diagram of system

\section{A. Sensors Description}

1) MQ135 Air Quality: Air quality sensor for detecting a wide range of gases, including NH3, NOx, alcohol, benzene, smoke and $\mathrm{CO} 2$.

2) MQ 4 Methane Sensor: Gas sensor has high to Methane, also to Propane and Butane.

3) $M Q 7 C O$ Carbon Monoxide Sensor: Carbon Monoxide (CO) sensor, suitable for sensing Carbon Monoxide concentrations (PPM) in the air.

4) MQ 6 Gas Sensor: The MQ-6 can detect gas concentrations anywhere from 200 to 10000ppm.

5) $M Q 2$ Gas Sensor: MQ2 gas sensor is used for sensing the concentration of gases such as smoke and carbon monoxide, $L P G$.

6) GPS sensor: GPS Sensor will help to get user location, to search nearby safe area,. Gives Hospital location guide in case of emergency

\section{B. Hardware Setup}

Figure 2 shows the Arduino board is connected to MQ135, MQ2, MQ 4, MQ 7, MQ 6 sensors.

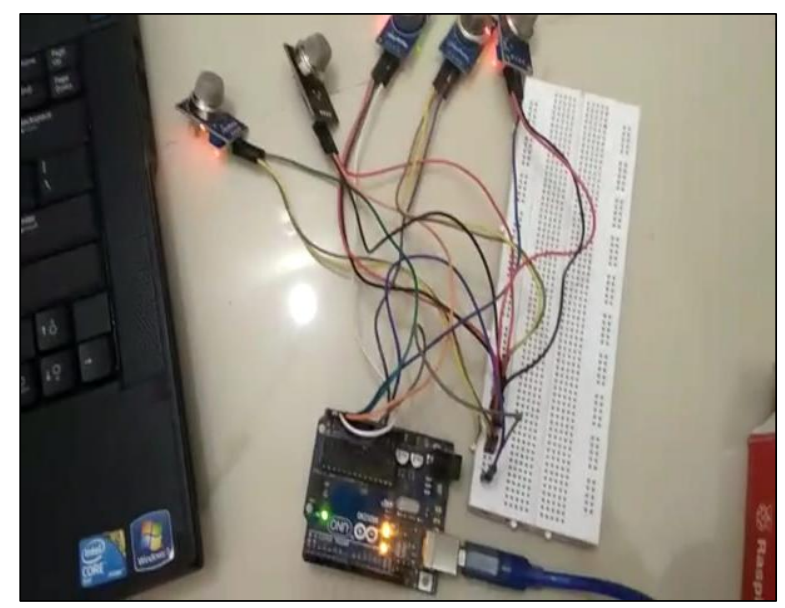

Fig. 2. Sensor connectivity with Arduino

\section{RESULT}

The following results have been achieved after installing hardware. User can sign in, set password. After login homepage will be displayed. In the menu bar user can click on the scan button to scan to environment.

\section{A. Scanning Phase}

The scanning phase is shown in two ways Rate scale and Bar chart. Figure 3 shows the rate scale in which user can check the status of the environment and all the gases present is displayed with their corresponding values.

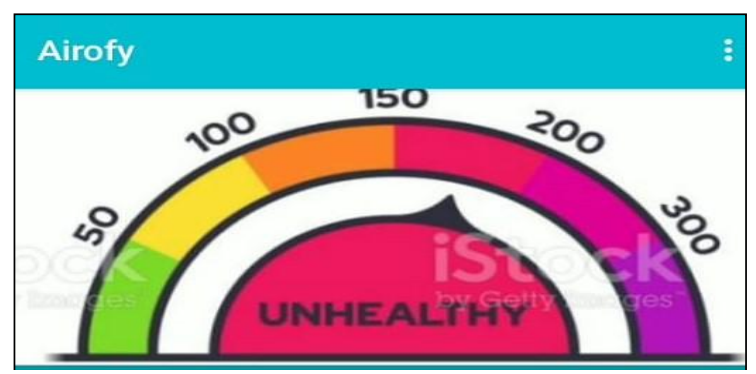

Fig. 3. Rate scale 


\section{B. Bar chart}

The bar chart shows the sensor value in a graphical format which is easier to visualize. By using bar chart values can be compared and user can see which gas is present most.

Fig 4 shows MQ6 Gas sensor is highly present.

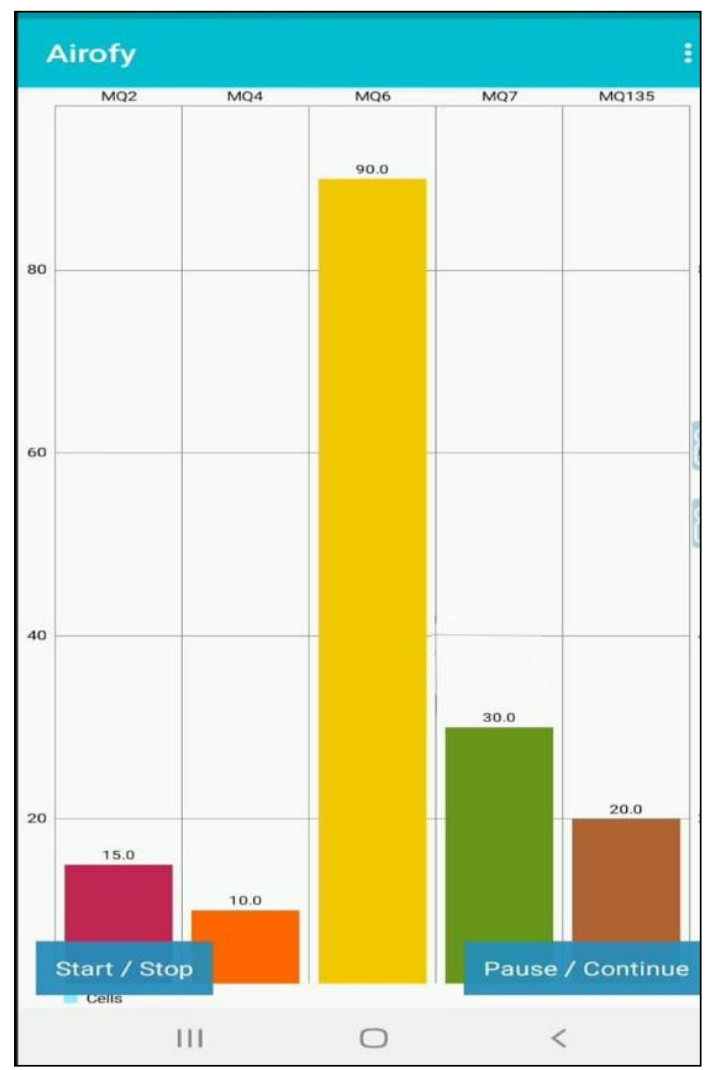

Fig. 4. Bar Graph.

\section{Prediction}

The KNN algorithm is used to predict the air status according to the scanning result obtained in the scanning phase. Here in KNN, the new point is assigned a value

based on how closely it resembles the points in the training set. The dataset is divided into 80:20 ratio where $80 \%$ is the training dataset and $20 \%$ is the testing dataset.

The distance between the new point and each training point is calculated first. The subsequent step is to choose a value for $\mathrm{k}$. Finding the value of $\mathrm{k}$ in $\mathrm{KNN}$ is difficult. A small value of $\mathrm{k}$ indicates that noise has a greater impact on the output, whereas a large value indicates that it is computationally costly.

\section{If the number of classes is two, it is an odd number.}

\section{Another method for determining $\mathrm{k}$ is to set}

For very small values of $\mathrm{k}$, the model over fits on the training data, resulting in a high error rate on the validation set. For a large number of k, however, the model performs badly on both the train and validation sets.

For this prediction model, the dataset contains dependent variable and independent variables. So here, status is a dependent variable and all the sensors values and time are independent variables.
As the sensor value changes, status of the air also changes and it will predict the status of the air whether there is low risk, moderate risk, and high risk.

In case high risk is detected, an alert sound or beep to notify the user about the bad status of air.

\section{AI Bot}

The AI bot can communicate with user in three ways image, audio and text. User can chat with the bot for asking questions for example "How to check the air status" etc. AI bot will also provide user with the safest nearest position in case of emergency as soon as user will login they will be asked to give location access. With the help of GPS Electrobot Ublox Neo 6m GPS sensor the system will find the nearest safest position for the user in case of emergencies like gas leak.

\section{CONCLUSION}

Overall, the application is a need of this hour as we know pollution in the environment is increasing at very large huge rate. The risk of road accidents, including gas trucks, has also risen due to a rise in the number of vehicles.. By using this application, the users will not only get an alert message prior to explosive action but also, they will receive a proper guidance in reaching to the safe destination. Not only in serious situations, this application also notifies the user with their current status and gives them tips on how to be more on the safer side.

In future, this application can be extended to the Iphone users as currently it's an android based application. Also, as per the increase to requirement it can also be extended as website.

\section{ACKNOWLEDGMENT}

The authors are grateful to the authorities of Dr D.Y.Patil School of engineering and Technology for assisting this project work.

\section{REFERENCES}

[1] Ajitesh Kumar, Mona Kumari and Harsh Gupta "Design and Analysis of IoT based air quality monitoring system" Feb 28-29, 2020

[2] Pratishtha Agnihotri, Sonam Tiwari and Dr. Devendra Mohan" Design of Air pollution monitoring system using wireless sensor network" 2019.

[3] Ravi Kishore Kodali and Sairi pathuri Sasweth C. Rajnarayanan "Smart Indoor air pollution monitoring station" Jan 22-24 2020, Coimbatore India.

[4] Zixuan Bai "Real time prediction for Fine-grained air quality monitoring system with asynchronous sensing", Perking university 2019.

[5] Mykhailo Lobur and Dmytro Korpyljov and Nazariy Jaworski "Arduino Based Ambient Air Pollution Sensing System" University of Exeter, 2020.

[6] Md. Mohiuddin Ahmed, Suraiya Banu and Bijan Paul"Real-time Air Quality Monitoring System for Bangladesh's perspective based on Internet of things " International Conference on Electrical Information and Communication Technology (EICT), 7-9 December 2017.

[7] Octavian A. Postolache, J. M. Dias Pereira, and P. M. B. Silva Girão" Smart Sensors Network for Air Quality Monitoring Applications "September 2009.

[8] Somansh Kumar and Ashish Jasuja "Air Quality Monitoring System Based on IoT using Raspberry Pi International Conference on Computing, Communication and Automation (ICCCA2017). 
[9] Ajay Chaturvedi and Laxmi Shrivastava "IOT Based Wireless Sensor Network for Air Pollution Monitoring "Jan 2020.

[10] JunHo Jo, ByungWan Jo, JungHoon Kim, SungJun Kim and WoonYong Han "Development of an IoT-Based Indoor Air Quality Monitoring Platform" January 2020. 